\title{
EFEITO DA POMADA DE BARBATIMÃO (STRYPHNODENDROM BARBATIMAN MARTIUS) ASSOCIADO AO ULTRASSOM DE BAIXA INTENSIDADE SOBRE A CICATRIZAÇÃO POR SEGUNDA INTENÇÃO DE LESÕES CUTÂNEAS TOTAIS EM RATOS
}

BALLABEN, Anelise Stella. Biomédica. CRISCI, Ana Rosa. Mestre. E-mail: criscicozac@ netsite.com.br. JORGE, Maria Helena Simões. Mestre. Centro Universitário Barão de Mauá. Rua: Ramos de Azevedo, 425, Jardim Paulista. CEP 14090-180, Ribeirão Preto-SP.

\section{RESUMO}

Pesquisas relacionadas ao tratamento de feridas cutâneas são motivo de interesse de pesquisadores, que buscam novos produtos e tecnologias com a possibilidade de acelerar o processo cicatricial. A presente pesquisa teve por objetivo analisar a ação cicatrizante da pomada de barbatimão a 5\% (Stryphnodendrom barbatiman Martius), associada ao ultrassom pulsado - USP de baixa intensidade, no modelo de cicatrização por segunda intenção. Foram utilizados 24 ratos Wistar (250-300g), divididos em 4 grupos: A: o grupo controle; B: tratadocom Barbatimão; C: foi tratado com USP; e D: aplicação de USP associado com Barbatimão. Após anestesia com cloridrato de Ketamina $100 \mathrm{mg} / \mathrm{kg}$ e cloridrato de Xilazima $6 \mathrm{mg} / \mathrm{kg}$, foi realizada a tricotomia da região dorsal de cada animal, seguida se uma lesão cortante de aproximadamente $1,0 \mathrm{~cm}^{2}$, que atingiu o tecido subcutâneo. Observou-se que o USP apresentou maior poder de cicatrização nos cinco primeiros dias de tratamento $(\mathrm{p}=0,1)$, comparadocom o barbatimão $(\mathrm{p}=0,2)$. Porém, nos dez dias de lesão, o barbatimão apresentou-se mais eficiente $(\mathrm{p}=0,3)$ quando comparado ao USP ( $\mathrm{p}=0,9)$. Já a associação de ambos não mostrou capacidade de acelerar a cicatrização. Observou-se que ambos os tratamentos têm poder cicatrizante quando usados isoladamente.

Palavras-Chave: Stryphnodendron barbatimam; Terapia por ultrassom; Cicatrização.

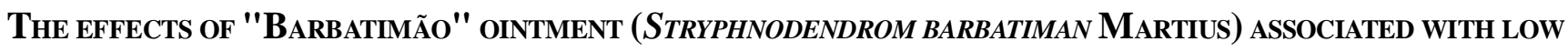
INTENSITY ULTRASOUND ON THE HEALING OF TOTAL CUTANEOUS LESIONS IN RATS

\begin{abstract}
Related researches for the treatment of skin wounds is a matter of interest to researchers seeking new products and technology with the possibility of accelerating the healing process. The present study had as aim to analyze the healing action of "Barbatimão" ointment at 5\% (Stryphnodendrom Barbatiman Martius) associated with low intensity pulsed ultrasound on the second intention healing process. The experiment was carried out using 24 Wistar rats (250-300g) divided into 4 groups: A was the control group, B: was treated with Barbatiman ointment, C: with pulsating ultrasound and D: with a combination of pulsating ultrasound and Barbatiman ointment. After anaesthesia with Ketamin $100 \mathrm{~g} / \mathrm{kg}$ and Xilamin chlorohidrate $6 \mathrm{mg} / \mathrm{kg}$, the dorsal region of the animal was shaved and an approximate $1.0 \mathrm{~cm}^{2}$ incision into the subcutaneous tissue was made. It was seen that in the first 5 days of treatment $(\mathrm{p}=0,1)$ the pulsating Ultrasound presented the best healing when compared to the "Barbatimão" ointment ( $\mathrm{p}=0.2)$. However, after 10 days the lesions treated with "Barbatimão" showed that this treatment was better $(\mathrm{p}=0.3$ ) compared to the pulsating ultrasound $(\mathrm{p}=0.9)$, but the association of the two types of treatments was not as successful at accelerating the healing process. Thus it was determined that separately they were more efficient at healing wounds.
\end{abstract}

KEYWORDS: Stryphnodendrom barbatiman; Ultrasound therapy; Healing. 


\section{INTRODUÇÃo}

A cicatrização tecidual é um processo dinâmico, independentemente de como foi induzida, seja por traumatismo ou por qualquer tipo de procedimento cirúrgico. Esse processo envolve uma série de fenômenos, como a inflamação, quimiotaxia, proliferação celular, diferenciação celular. Quando o processo inflamatório não pode ser eliminado, desencadeia-se uma resposta complexa, que pode levar a uma inflamação crônica (GONÇALVES e PARIZOTTO, 1998; BALBINO et al., 2005; STEVENS e LOWE, 2000; KUMAR et al., 2005).

Devido a isso, um arsenal terapêutico tem se desenvolvido, nos últimos anos, não somente com substâncias sintéticas, como também com a incorporação de fitoterápicos, inclusive com alguns já testados e apresentando resultados significativos (GARROS et al., 2006). Vários estudos com extratos de plantas têm sido utilizados como atividades cicatrizantes, antimicrobianas e imunomoduladora (ATES e ERDOÚRUL, 2003; ARORA e KAUR, 2004; AMIRGHOFRAN et al., 2009).

O barbatimão é uma planta nativa do Cerrado brasileiro, que contém alto teor de taninos que lhe proporcionam ação adstringente, antisséptica, antioxidante e cicatrizantes (FARIA, 1992). É uma árvore que cresce de maneira isolada e, das 26 espécies dessa árvore, 25 são nativas do Brasil.

Pelo fato de o barbatimão possuir propriedades adstringentes, permite que haja a formação de um revestimento protetor que impede a multiplicação de bactérias e, consequentemente, age como uma assepsia. Isso tudo é devido à precipitação das proteínas das células superficiais da mucosa e dos tecidos lesados desprotegidos (COSTA, 1986).

Inúmeras plantas são utilizadas com atividades cicatrizantes, como a Calendula officinales (calêndula) (FLEISCHNER, 1985), a Eclipta alba (agrião-de-brejo), o Symphytum officinale (confrei) e o Stryphnodendron adstringens (NETO et al., 1996).

De acordo com Jorge Neto et al. (1996), existem trabalhos que já descreveram a grande eficiência no tratamento de úlcera varicosa , devido a associação do barbatimão com a calêndula. Silva (2006), trabalhando com gatas ovariohisterectomizadas, verificou que os curativos com iodopovidona e barbatimão apresentaram o mesmo tempo de cicatrização, quando comparados entre si, demonstrando que o fitoterápico possui ação cicatrizante confiável.

Estudos realizados com a utilização da pomada contendo $3 \%$ de fito completo fenólica de barbatimão mostram que a cicatrização de lesões de grau I e II ocorreu em um período de 3 a 6 semanas e as de grau III, entre 10 e 18 semanas. Todas as lesões tratadas com a pomada cicatrizaram completamente (MINATEL et al., 2010). Entretanto, estão sendo introduzidas, terapias físicas, como o ultrassom pulsado de baixa intensidade, que minimiza o risco de lesões teciduais, que podem ocorrer com intensidades elevadas e com o modo contínuo (FERREIRA et al., 2008; MENDONÇA et al., 2006). Recentemente, esses efeitos benéficos foram relacionados à irradiação ultrassônica pulsada de baixa intensidade sobre o processo de cicatrização e regeneração de diferentes tecidos (MENDONÇA et al., 2006).

Utilizado no tratamento de lesões de tecidos moles, o ultrassom pode acelerar a reparação tecidual nas suas diferentes fases, sendo possível melhorar tanto a velocidade da cicatrização, quanto a qualidade do tecido cicatricial (inflamação aguda, proliferação e remodelação) desde o seu início, liberando histaminas e fatores de crescimento, pela degranulação de macrófagos, mastócitos e plaquetas. Além disso, ocorre também um aumento de colágeno, pois os fibroblastos e as células endoteliais sofrem ação do ultrassom e, com isso, o tecido fica mais resistente à ação da tração (FERREIRA et al., 2008).

Dados na literatura quanto ao uso combinado do ultrassom pulsado - USP com alguma substância química para a cicatrização de feridas são escassos. Camargo (2007) associou o USP com papaína em forma de gel em úlceras de pressão, porém, esta era para evitar a aderência da gaze e facilitar a remoção do curativo sem dor para os pacientes, obtendo assim 
resultados significativos.

A proposta é, portanto, verificar se o processo de cicatrização se torna mais eficaz por meio da associação dos dois tratamentos: o ultrassom pulsado de baixa intensidade com a pomada de barbatimão, com a finalidade de serem utilizados pela equipe de saúde como um tratamento inovador e não invasivo, para a redução do tempo de cicatrização da pele.

\section{Materiais e Método}

Foram utilizados neste experimento 24 ratos com variação de $250 \mathrm{~g}$ a $300 \mathrm{~g}$ de peso, divididos em 4 grupos. Os ratos foram anestesiados com aplicação de $0,2 \mathrm{mg} / \mathrm{kg}$ de cloridrato de xilazina $2 \%$ (rompum) e $0,3 \mathrm{mg} / \mathrm{kg}$ de cloridrato de ketamina $10 \%$, para a realização da lesão na pele.

A lesão foi realizada na região dorsal; inicialmente, foi feita a tricotomia e a delimitação de uma área de 1 $\mathrm{cm}^{2}$, onde foi realizada a lesão com o auxílio de bisturi ou tesoura apropriada (Figura 1).

No grupo controle (grupo A), formado por oito ratos, após a lesão cirúrgica, foi aplicado soro fisiológico apenas para manter a hidratação do local. Desse grupo, quatro animais foram sacrificados após cinco dias da lesão e os outros quatro foram sacrificados dez dias após a lesão.

No grupo B experimental, com oito ratos, após a lesão cirúrgica, os animais receberam a aplicação da pomada Fitoscar (Stryphanodendron adstringens (Mart.) Covelle.), extrato seco 5\% do laboratório Apsen (Figuras 2C e D), sendo que, destes animais, quatro foram sacrificados cinco dias após a lesão e os outros quatro foram sacrificados dez dias após a lesão.

Os quatro animais do grupo $\mathrm{C}$ foram submetidos, após a lesão, a aplicações diárias de USP por cinco minutos, sempre no mesmo horário, e da mesma maneira dois deles foram sacrificados cinco dias após a lesão e os outros dois animais, dez dias após a lesão.

No último grupo, o D, os quatro animais foram submetidos, após a lesão, à aplicação da pomada Fitoscar, associada a aplicações diárias de ultrassom de baixa intensidade por cinco minutos, sempre no mesmo horário (Figuras 2A e B); dois foram sacrificados cinco dias após a lesão e os outros dois, dez dias após a lesão.

Portanto, o sacrifício dos animais em câmara de dióxido de carbono, conforme aprovação do Comitê de ética Animal, foi realizado no $5 .^{\circ}$ e $10 .^{\circ}$ dias do experimento, para a avaliação do processo cicatricial nesses intervalos.

Após a eutanásia dos animais, as regiões lesionadas foram retiradas, fixadas em formol $10 \%$ e processadas pelas técnicas histológicas de rotina. As colorações feitas foram: Hematoxilina e eosina. Os cortes histológicos foram analisados sob microscopia óptica e as fotomicrografias realizadas através de fotomicroscópio, para a identificação das áreas de cicatrização.

Os dados histopatológicos foram transformados em escores e quantificados de acordo com a técnica de MYERS modificada. A soma dos produtos da Tabela 1, a seguir, correspondeu ao escore total para cada animal. Os resultados foram avaliados por análise de variância, para determinar as diferenças existentes entre os grupos, foi feito um teste não paramétrico de Kruskal-Wallis. (apêndice). Foram consideradas significativas comparações com $\mathrm{P}$ igual ou menor a 0,05 $\left(\mathrm{p}<0,05^{*}\right)$. 
Tabela 1 - Variáveis e escores (Método de Myers).

\begin{tabular}{|l|c|l|c|c|c|} 
Variáveis & $\begin{array}{c}\mathbf{0}- \\
\text { ausente }\end{array}$ & $\mathbf{+ 1}$ - leve & $\begin{array}{c}\mathbf{+ 2}- \\
\text { moderado }\end{array}$ & $\begin{array}{c}\mathbf{+ 4} \\
\text { maciço }\end{array}$ & Fator \\
\hline abcesso & & & & & -10 \\
\hline crosta & & & & & -1 \\
\hline $\begin{array}{l}\text { regeneração } \\
\text { epitelial }\end{array}$ & & & & & +5 \\
\hline fibroblastos & & & & & +5 \\
\hline tecido granulação & & & & & +5 \\
\hline colágeno & & & & & +10 \\
\hline Escore total & & & & & \\
\hline
\end{tabular}

Fonte: Medeiros et al., 1999. 
Efeito da Pomada de barbatimão...
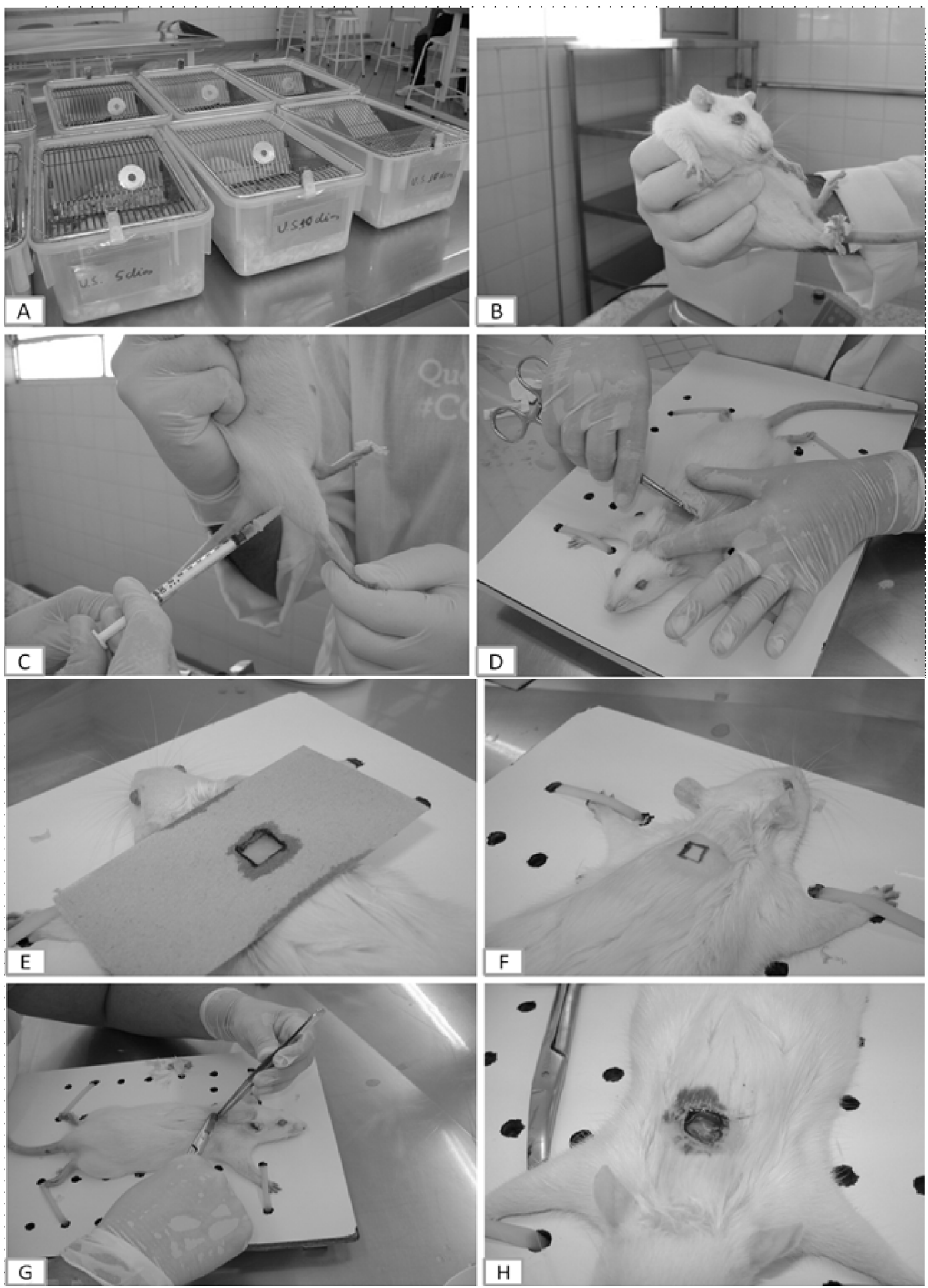

Figura 1 - Etapas dos procedimentos cirúgicos: $\mathbf{E m} \mathbf{A}$ :animais em gaiolas individuais e identificadas, $\mathbf{E m} \mathbf{B}$ : manipulação para anaestesia, Em C : anestesia, Em D: tricotomia, Em E: padronização dos cortes, Em F: marcação do corte, $\mathbf{E m ~ G : ~ p r o c e d i m e n t o ~ c i r u ́ r g i c o , ~ E m ~ H : ~ f i n a l i z a c ̧ a ̃ o ~ d a ~ l e s a ̃ o . ~}$

Fonte: Dados de pesquisa. 

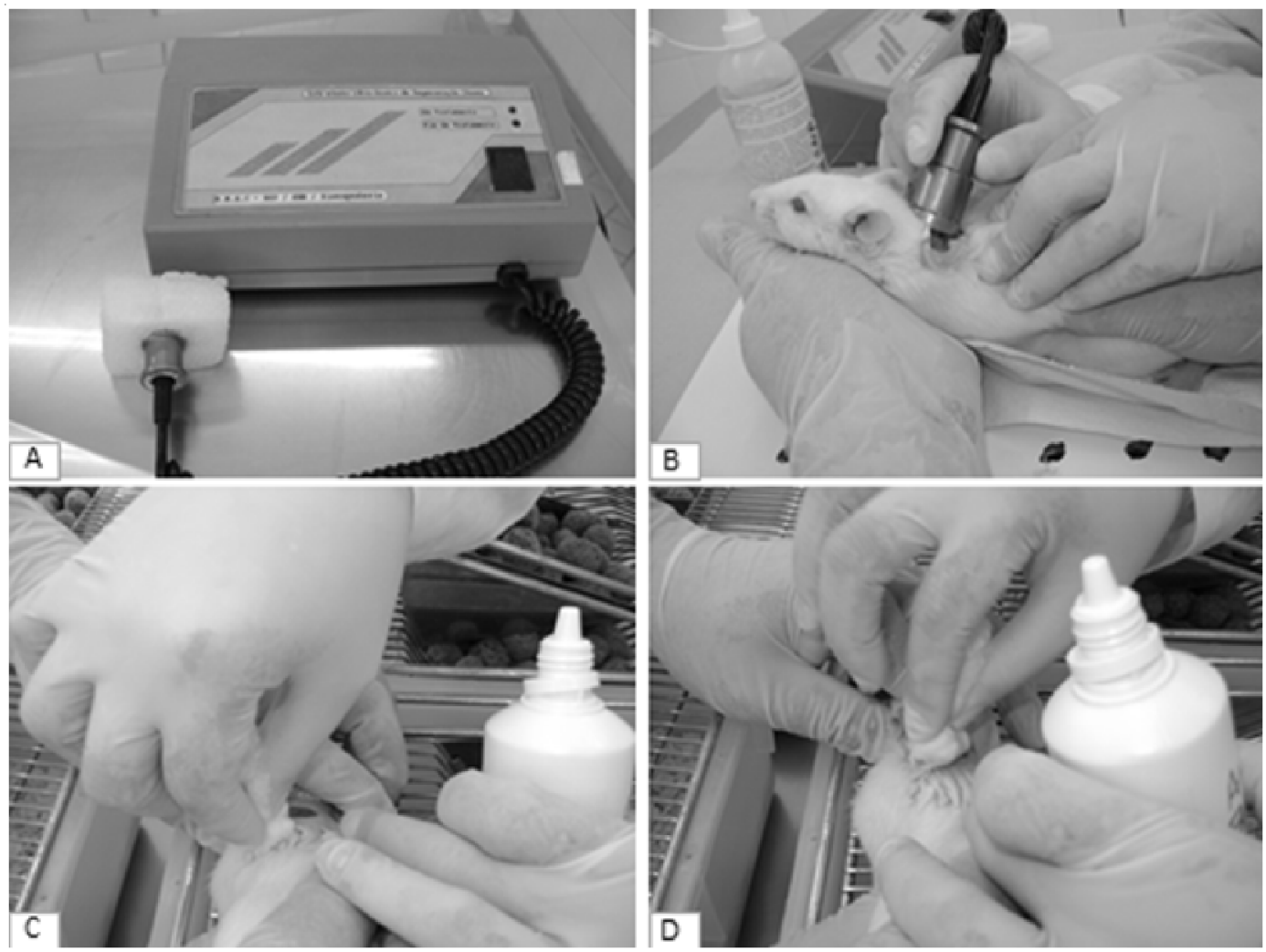

Figura 2 - Etapas das aplicações diárias. Em A: Aparelho de USP utilizado no experimento. Em B:

Aplicação de ondas ultrassonicas. Em C e D: Aplicação da pomada de barbatimão.

Fonte: Dados de pesquisa.

\section{Resultados}

Durante os cinco primeiros dias de tratamento, observou-se na análise histopatológica das áreas dos animais do grupo tratado (Figuras 3B,4B e 5B), com pomada de barbatimão, uma grande vascularização ( seta curta) e presença de crosta fibrino-leucocitária (asterisco), infiltrado inflamatório (seta pontilhada), formação de neovasos (seta curta) e presença de fibroblastos (seta vasada).

Durante os cinco primeiros dias de tratamento, observou-se na análise histopatológica das áreas dos animais do grupo tratado com o ultrassom pulsado de baixa intensidade (Figuras 3C, 4C e 5C) a presença de infiltrado inflamatório (seta pontilhada) e crosta fibrino-leucocitária (asterisco), e presença de grande número de polimorfonucleares (seta pontilhada).

Durante os cinco primeiros dias de tratamento, observou-se na análise histopatológica das áreas dos animais tratados com a associação dos tratamentos (Figuras 3D, 4D e 5D) a presença de infiltrado inflamatório (seta pontilhada), poucos vasos neoformados (seta curta) e muitos polimorfonucleares (seta pontilhada).

Durante os cinco primeiros dias de tratamento, observou-se na análise histopatológica das áreas dos animais do grupo controle (Figuras 3A, 4 A e 5A), que recebeu apenas soro fisiológico como tratamento tópico, a presença de crosta fibrino-leucocitária (*) completamente solta da região lesada e infiltrado leucocitário (seta pontilhada) e presença de grande número de polimorfonucleares (seta pontilhada). 


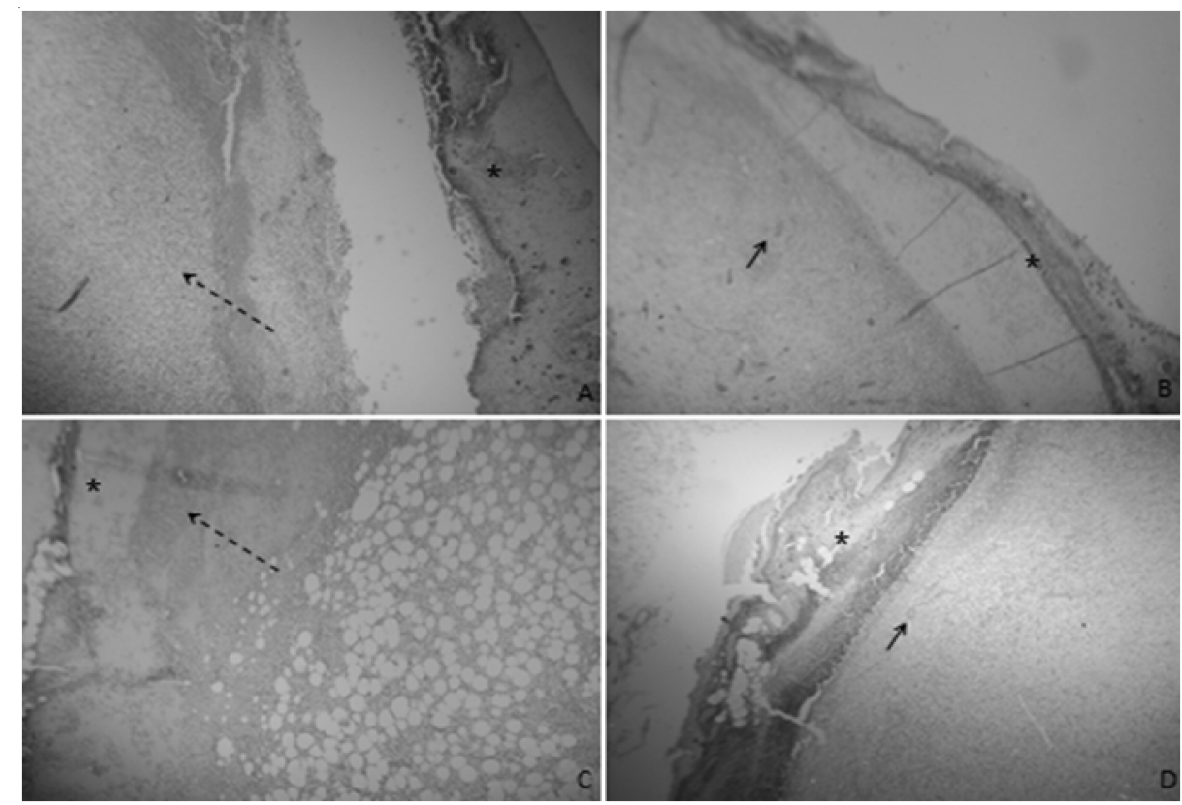

Figura 3 - Fotomicrografias dos aspectos histopatológicos das feridas com 5 dias de tratamento (H.E.)(Pan 4x) EmA: grupo controle, em B: grupo tratado com barbatimão, Em C: grupo tratado com USP, em D: grupo tratado com USP e barbatimão.Presença de crosta fibrino-leucocitária (*), Infiltrado leucocitário (seta pontilhada), neovascularização (seta curta). Aumento final 40x.

Fonte: Dados de pesquisa.
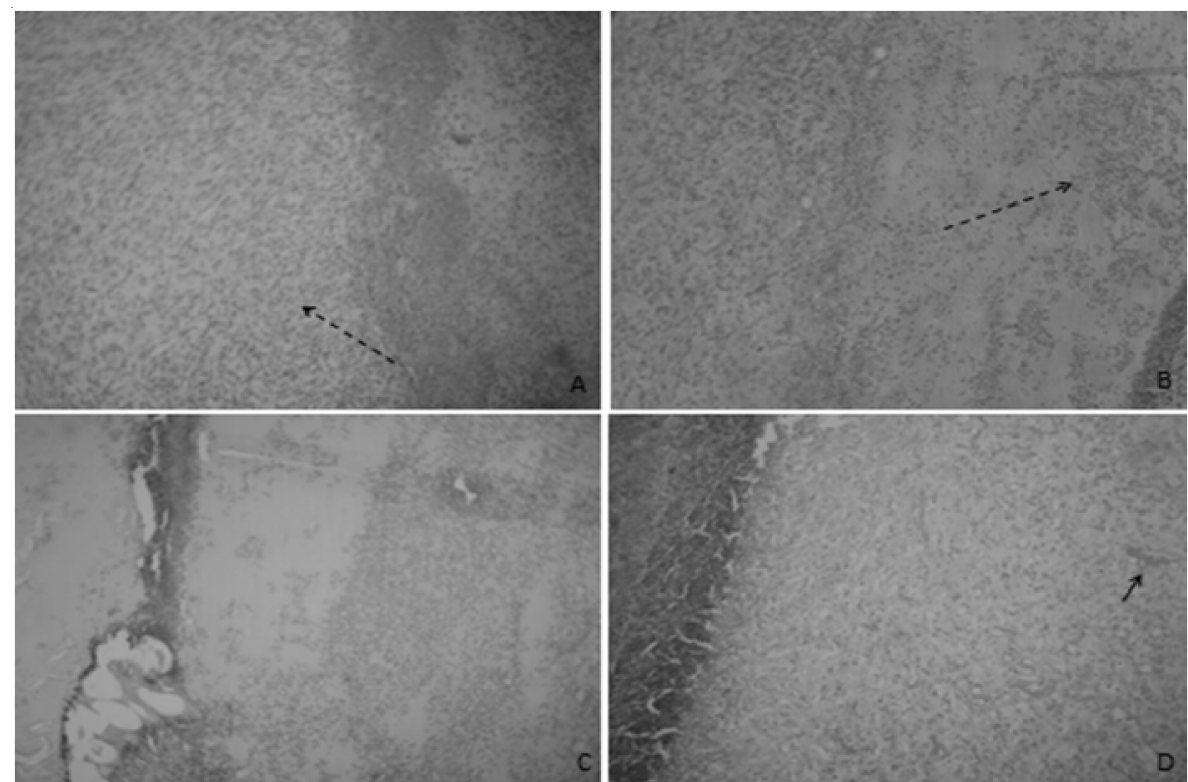

Figura 4 - Fotomicrografias dos aspectos histopatológicos das feridas com 5 dias de tratamento (H.E.)(10x). Em A: grupo controle, em B: grupo tratado com barbatimão, Em C: grupo tratado com USP, em D: grupo tratado com USP e barbatimão. Presença de, Infiltrado leucocitário (seta pontilhada), neovascularização (seta curta). ) Aumento final 40x.

Fonte: Dados de pesquisa. 

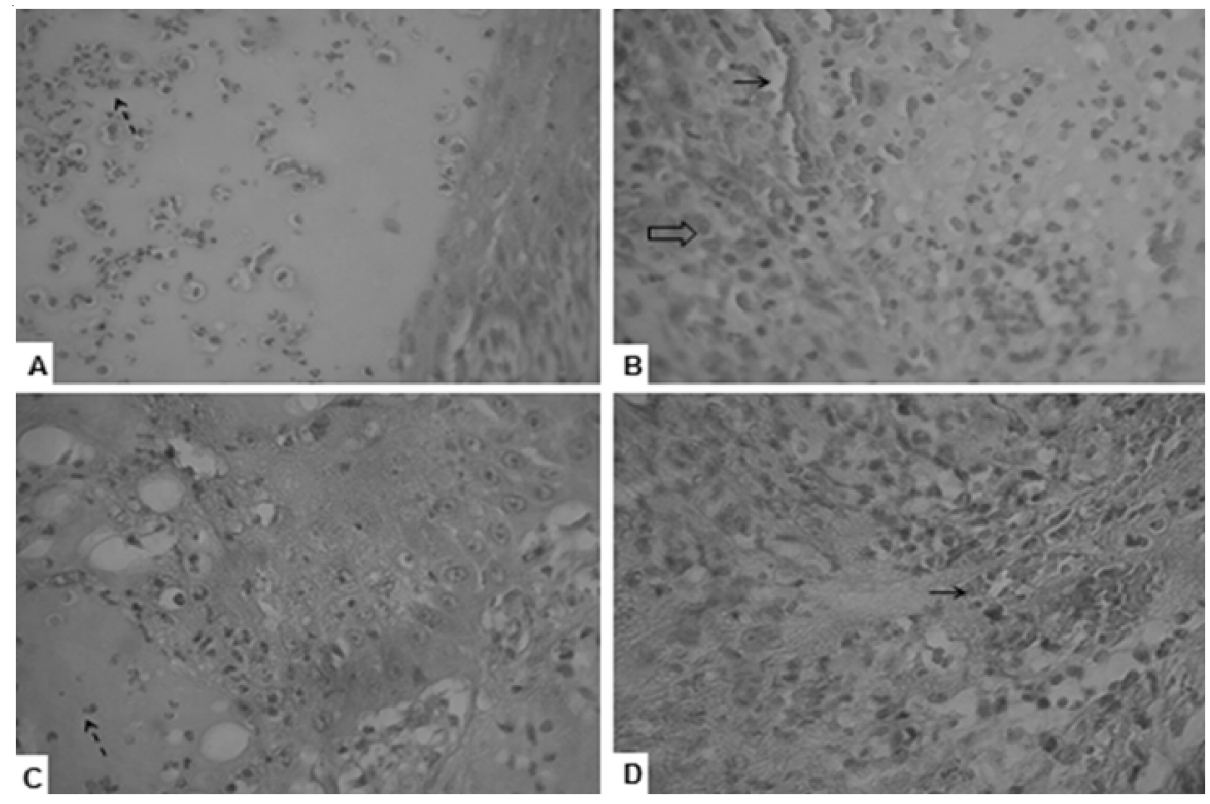

Figura 5 - Fotomicrografias dos aspectos histopatológicos das feridas com 5 dias de tratamento (H.E.)( 40x). Em A: grupo controle, em B: grupo tratado combarbatimão, Em C: grupo tratado com USP, em D: grupo tratado com USP e barbatimão. Presença de polimorfonucleares (seta curta pontilhada), fibroblastos(seta vasada) e neovasos( seta curta). Aumento final 400x.

Fonte: Dados de pesquisa.

A análise histopatológica dos animais tratados durante dez dias com pomada de barbatimão (Figuras 6B, 7B e 8B) mostra tecido epitelial refeito e totalmente aderido à derme (seta cheia), presença de crosta solta do tecido reepitelizado (asterisco), presença de fibroblastos (seta vasada) e disposição homogênea de fibras colágenas $(*)$.

$\mathrm{Na}$ análise histopatológica dos animais tratados durante dez dias com ultrassom pulsado de baixa intensidade (Figuras 6C, 7C e 8C), observou-se grande quantidade de fibroblastos (seta vasada), crosta fibrinoleucocitária completamente desprendida (asterisco), reepitelização completa (seta cheia) e grande quantidade de neovasos (seta curta).
$\mathrm{Na}$ análise histopatológica dos animais tratados durante dez dias com tratamento associado (Figuras 6D, 7D e 8D) notou-se a ausência de crosta fibrinoleucocitária, uma reepitelização completa (seta cheia), uma grande quantidade de fibroblastos alinhados (seta vasada), assim com uma maior vascularização (seta curta) quando comparada com os outros tipos de tratamento.

A análise histopatológica dos animais tratados durante dez dias (Figuras $6 \mathrm{~A}, 7 \mathrm{Ae} \mathrm{e}$ 8) apenas com soro fisiológico como tratamento tópico mostra a presença de crosta fibrino-leucocitária ainda muito aderida ao epitélio (asterisco), a reepitelização mais atrasada emrelação aos demais tratamentos (seta cheia) e a presença de fibroblastos. 
Efeito da Pomada de barbatimão...
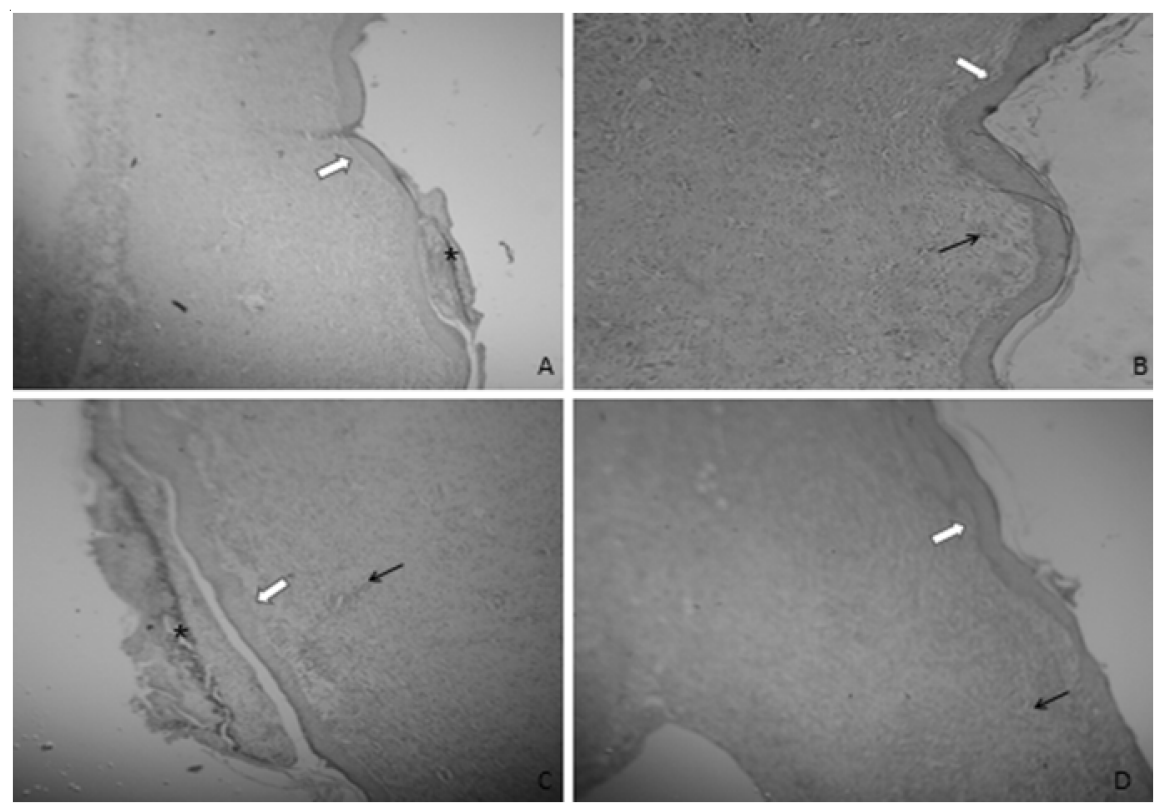

Figura 6 - Fotomicrografias dos aspectos histopatológicos das feridas com 10 dias de tratamento (H.E.) (Pan). Em A: grupo controle, em B: grupo tratado com barbatimão, Em C: grupo tratado com USP, em D: grupo tratado com USP e barbatimão.Presença de crosta fibrino-leucocitária (*), neovascularização (seta curta), reepitelização (seta cheia). Aumento final 100x.

Fonte: Dados de pesquisa.
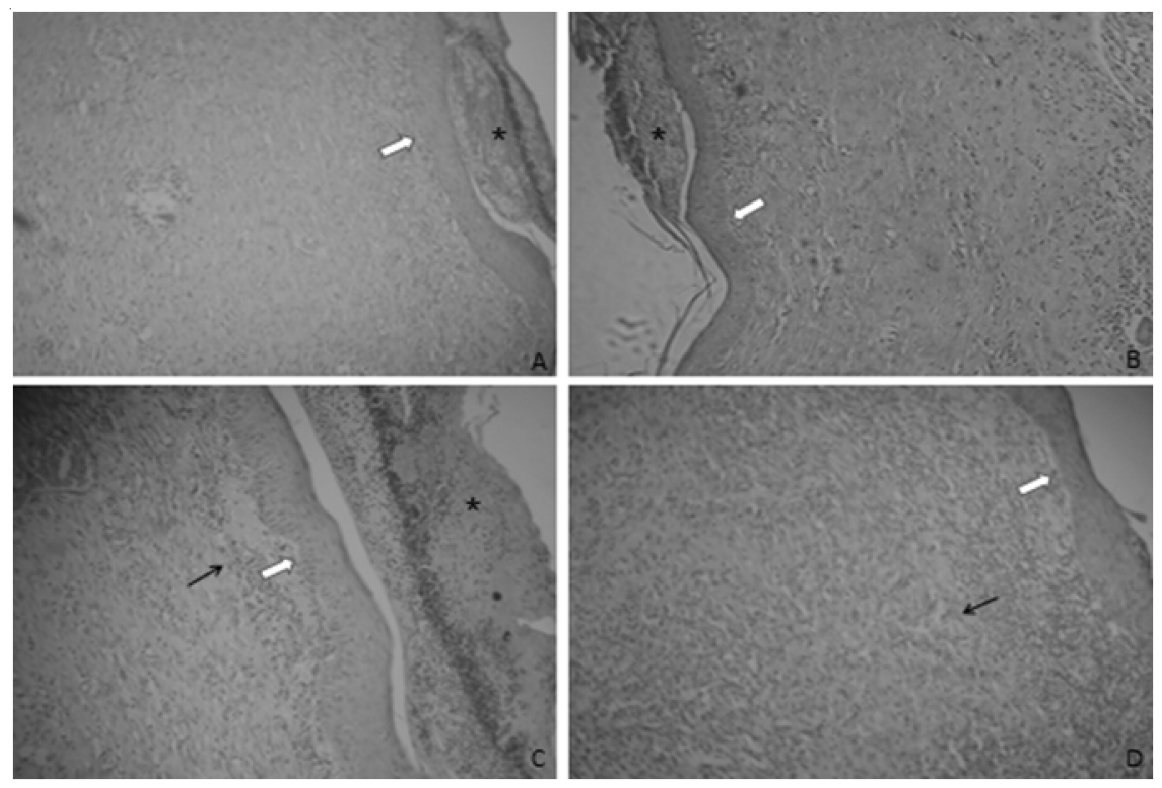

Figura 7 - Fotomicrografias dos aspectos histopatológicos das feridas com 10 dias de tratamento (H.E.) (10x). Em A: Controle, em B: grupo tratado com barbatimão, Em C: grupo tratado com USP, em D: grupo tratado com USP e barbatimão. Presença de neovascularização (seta curta), crosta fibrino-leucocitária (*) e reepitelização (seta cheia) Aumento final 100x.

Fonte: Dados de pesquisa. 

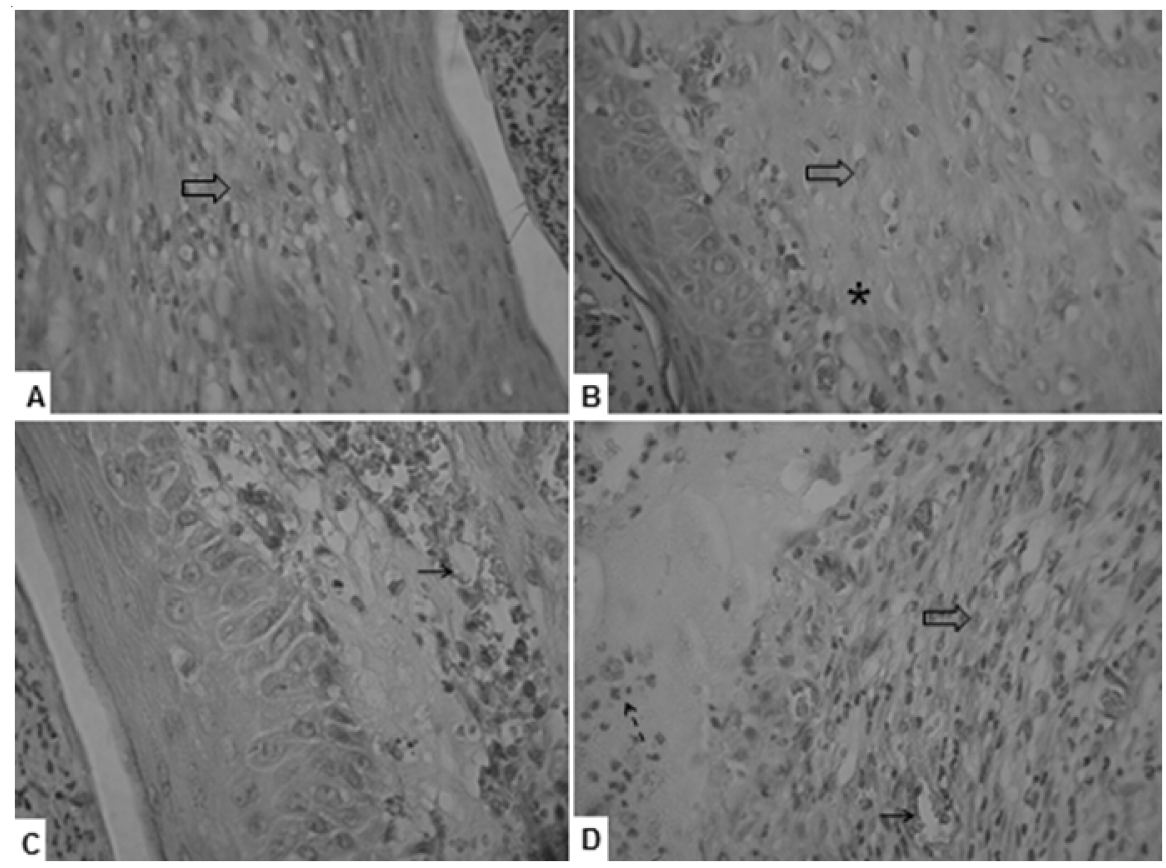

Figura 8 - Fotomicrografias dos aspectos histopatológicos das feridas com 10 dias de tratamento (H.E.)( 40x). Em A: grupo controle, em B: grupo tratado com barbatimão, Em C: grupo tratado com USP, em D: grupo tratado com USP e barbatimão. Presença de fibroblastos (seta vasada) e neovasos (seta curta) e fibras colágenas $(*)$. Aumento final 400x.

Fonte: Dados de pesquisa.

Para as avaliações estatísticas foi aplicado o teste Kruskal-Wallis (análise de variância não-paramétrica ou teste não-paramétrico para comparação de médias de mais de dois grupos). Esse teste não-paramétrico foi utilizado devido ao tamanho reduzido das amostras para cada tratamento, e não foi verificada distribuição gaussiana para os dados.

O teste de comparação de médias foi realizado para comparar os escores médios obtidos como tratamento feito com a pomada de barbatimão, o tratamento com USP, coma associação de ambos e como grupo controle. Devido ao pequeno tamanho amostral, não houve diferença estatística significante nos tratamentos aplicados: os resultados obtidos foram $\mathrm{p}=0,1437$ aos cinco dias de tratamento e $\mathrm{p}=0,6821$ aos dez dias de tratamento.

Foram feitas outras análises: o grupo controle, comparado com o grupo que foi tratado com a pomada de barbatimão durante cinco dias, foi $\mathrm{p}=0,2$; com o
USP foi $\mathrm{p}=0,1333 \mathrm{e}$, com a associação de ambos, foi $\mathrm{p}=0,9999$. O grupo controle, comparado como grupo que foi tratado com a pomada de barbatimão durante dez dias, resultou em $\mathrm{p}=0,3429$; com o USP foi $\mathrm{p}=$ 0,9999 e, com a associação de ambos, foi $p=0,8$.

Com essas análises também não conseguimos diferença estatística significativa, devido à pequena amostragem de animais.

\section{Discussão}

Em concordância com Santos et al. (2002), a cicatrização é um processo que ocorre para garantir a reparação e o fechamento de uma área lesada.

Esse reparo tissular é um processo complexo, que envolve a interação entre células da matriz extracelular e circulatórias, ambas ativadas por diversos mediadores químicos, por elementos da própria matriz extracelular, por alterações de natureza física e química 
da região da lesão e de áreas circunjacentes. Embora didaticamente o processo de cicatrização seja dividido em três fases, elas se comportam independentemente e sequencialmente no tempo. Portanto, os eventos celulares, tissulares e metabólicos possuem uma cronologia pré-estabelecida (BALBINO et al., 2005).

Esse fato se torna relevante devido aos aspectos terapêuticos adotados, pois não seria correto, por exemplo, administrar um potencializador da migração de neutrófilos se a análise cronológica da lesão indicar que ocorre o predomínio da reepitelização. Sendo assim, muitas pesquisas devem ser realizadas no sentido de empregar a substância tópica, ou qualquer outra tecnologia que acelere o processo cicatricial normal, no tempo cronológico da lesão.

O que é feito de imediato é proteger a ferida de complicações físicas, químicas ou bacteriológicas que possam retardar o processo cicatricial (ARAUJO et al., 1994).

Foi, portanto, o objetivo primário desta investigação associar uma tecnologia conhecida e comprovadamente atuante nos processos cicatriciais, o USP pulsado de baixa intensidade, com uma substância química também conhecida e utilizada pelos profissionais da saúde, a pomada de barbatimão. O rato foi o modelo experimental escolhido por ser de fácil manutenção e manuseio, sendo também de dimensões adequadas à produção das lesões padronizadas e aos tipos de tratamentos propostos.

As lesões cutâneas foram extensas, com remoção completa da pele em área padronizada, expondo a fáscia do músculo subjacente do dorso do animal, para que não houvesse interferência dele no mecanismo de cicatrização. Após a retirada do fragmento de pele, ocorre a formação de uma solução de continuidade que é preenchida inicialmente por fibrina, coágulo e exsudato inflamatório, formando a crosta que recobre a ferida (BEVILACQUA et al. 1981; MARCHINI, 1994). Em nossos achados, todos os tipos de tratamento, inclusive no grupo controle, foi observada nos cinco primeiros dias da lesão a formação de exsudato inflamatório e crosta cobrindo a ferida.

Porém, resultados evidenciaram que a pomada de barbatimão, comparada com o controle, se mostrou mais eficiente nos primeiros cinco dias de tratamento $(\mathrm{p}=0,2)$, comparados aos dez dias de tratamento ( $p=0,3$ ), o que comprova sua propriedade cicatrizante e anti-inflamatória, segundo Favoreto et al. (1985), que também demonstraram a eficiência das preparações aquosas de barbatimão no tratamento de úlceras de contenção em ratos.

Young e Dyson (1990a) observaram que, desde o 5. ${ }^{\circ}$ dia da produção da lesão, havia um contingente muito menor de células inflamatórias. Foi o que se observou neste experimento, quando se comparou com o grupo controle. Porém, na associação da pomada de barbatimão com o ultrassom pulsado de baixa intensidade comparada com o controle, nos cinco primeiros dias, isso não foi possível observar: os resultados foram ainda menos significativos $(p=0,9)$, provavelmente por atuarem em fases da lesão cronologicamente diferentes.

O ultrassom pulsado de baixa intensidade, segundo Dyson,(1987), age nas fases do mecanismo fisiológico (inflamação aguda, proliferação e remodelação) desde o seu início, no qual promove a liberação de histamina e de fatores de crescimento, pela degranulação de macrófagos, mastócitos e plaquetas. Os fibroblastos e as células endoteliais também podem ser afetados pelo ultrassom, aumentando a síntese de colágeno, o que confere maior resistência do tecido à tração.

Nossos achados com o ultrassom pulsado de baixa intensidade, nos cinco primeiros dias de tratamento, foi melhor $(p=0,1)$, em comparação aos dez dias de tratamento $(\mathrm{p}=0,9)$.

$\mathrm{Na}$ associação da pomada de barbatimão com o ultrassom pulsado de baixa intensidade, em comparação com o controle, nos dez primeiros dias os resultados foram mais significativos $(p=0,8)$. Sugere-se que a diferença de efeito entre os tratamentos não foi detectada por causa do tamanho amostral limitado. Ferreira (2005), para verificar apenas os efeitos do ultrassom pulsado de baixa intensidade na cicatrização de lesões cutâneas por segunda intenção, utilizou 30 animais no seu grupo controle e 30 animais no grupo que recebeu o estímulo utrassônico - durante 
o experimento, 6 animais morrerame foram substituídos para manter a uniformidade dos grupos.

Como o mecanismo pelo qual o barbatimão estimula a proliferação celular dos queratinócitos na cicatrização ainda não é conhecido, de acordo com Santos (2002), sugerem-se novas investigações, com o objetivo de identificar qual a melhor fase para se usar a pomada de barbatimão.

Nossos achados se coadunam com investigações semelhantes que usaram o USP pulsado de baixa intensidade e a pomada de barbatimão isoladamente nos cinco primeiros dias da lesão e obtiveram resultados estatisticamente significativos. Embora aos dez dias após a lesão se observe uma reepitelização total com todos os tipos de tratamento, pode-se afirmar que a pomada de barbatimão é o tratamento mais eficiente.

Tendo em vista os resultados obtidos para o período compreendido entre o quinto e o décimo dias, ao se comparar a área de lesão nos grupos controle, com pomada de barbatimão e irradiado com o ultrassom pulsado de baixa intensidade e com a associação de ambos os tratamentos, sugere-se que novas pesquisas sejam conduzidas, no intuito de identificar em qual dia o grupo tratado com o ultrassom pulsado de baixa intensidade e o grupo tratado com a pomada de barbatimão sobre a cicatrização cutânea apresentam melhor eficácia, já que os métodos podem ser utilizados pelos profissionais dessas áreas, devido ao baixo custo e possibilidade de aplicações em domicílio.

\section{Conclusão}

É possível concluir que ambos os tratamentos são confiáveis, quando utilizados isoladamente. São de baixo custo e de fácil manuseio.

O ultrassom pulsado de baixa intensidade deve ser usado imediatamente após a lesão, pois é comprovadamente mais eficiente nos cinco primeiros dias da lesão, quando comparado com o grupo controle.

Com relação à pomada de barbatimão, pouco ainda se sabe sobre a fase exata da cicatrização em que ela atua, porém sabemos que, usada isoladamente durante nos dez primeiros dias da cicatrização, funciona como um ótimo cicatrizante.

\section{REFERÊNCIAS}

AMIRGHOFRAN, Z. et al. Immunomodulatory activies of various medicinal plant extracts: Effects on human lymphocytes apoptoses.

Immunological Investigation, v. 38, n. 2, p. 181-92, 2009.

ARAÚJO, C.F.R. et al. Efeitos do Agarol e do Triglicerol sobre a cicatrização de pele. Estudo experimental em ratos. Acta Cirúrgica Brasileira, v. 13, n. 4, p. 12, 1994.

ARORA, D.S.; KAUR, G.J. Antibacterial activity of some Indian medicinal plants. Journal of natural medicines, v. 61, p. 313-7, 2007.

ATES, D.A; ERDOÚRUL, Z.T. Antimicrobial activities of various medicinal and commercial plant extracts. Turkish journal of biologic, v. 27, p. 157-62, 2003.

BALBINO C.A., PEREIRA L.M. \& CURI R. (2005) Mecanismos envolvidos na cicatrização: uma revisão. Revista Brasileira de Ciências Farmacêuticas 41: 27-51.

BALBINO, C.A.; PEREIRA, L.M. ; CURI, R. Mecanismos envolvidos na cicatrização. Revista Brasileira Ciências Farmaceuticas, v. 41, n. 1, p. 27-51, 2005.

BEVILACQUA, R.G. et al. Cicatrização. In: GOLDENBERG, S.; BEVILACQUA, R.G. Bases da Cirurgia. São Paulo: EPM/ Springer; 1981,p. 99-116.

CAMARGO, S.M.P.L.O. Estudo combinado do ultra-som pulsado de baixa intensidade e da papaína na cicatrização de úlcera por pressão no atendimento domiciliar. 2007. 130 p. Dissertação (Mestrado em Bioengenharia) Universidade de São Paulo, USP, São Carlos. 
CARVALHO, D.C.L. et al. Tratamentos não farmacológicos na estimulação da osteogênese. Revista de Saúde Pública, v. 36, p. 647-654, 2002.

CORSI, R.C.C. et al. Cicatrização das feridas revisão da literatura. Revista Brasileira de Cirurgia, v. 84, n. 1, p. 17-24, 1994.

COSTA, A.F. Farmacognosia. 3.ed. Lisboa: Fundação Calouste Gulbekian, 1986. 1031p.

DIONÍSIO, V.C.; Volpon, J.B. Ação do ultra-som terapêutico sobre a vascularização pós-lesão muscular experimental em coelhos. Revista Brasileira de Fisioterapia, v.4, p.19-25, 1999.

DYSON, M. Mechanisms involved in therapeutic ultrasound. Physiotherapy. , v.73, n. 3, p. 116-120, 1987.

FARIA, D.M. Tanino: métodos de determinação e extração e usos. 1992. 35p. Monografia em ciências florestal. Departamento de Ciências Florestais, Universidade de Lavras. Lavras.

FARSNWORTH, N.R.; SOERJATO, D.D. Potencial consequence of plant exitintion in the United States on the current and future availability of prescription drugs. Economic Botany, v. 39, p. 231-240, 1985.

FAVORETO, L.V. et al. Ação cicatrizante do extrato aquoso da casca do barbatimão Stryphnodendron obovatum em úlcera de por contenção em ratos. Revista da Escola de Farmácia e Odontologia de Alfenas, v. 8, p. 7$12,1985$.

FERREIRA, A. S.; BARBIERI, C.H. ; MAZZER, N. ; CAMPOS, A.D. ; MENDONÇA, A.C.

Mensuração de área de cicatrização por planimetria após aplicação do ultra-som de baixa intensidade em pele de rato. Revista Brasileira de Fisioterapia, v. 5, n. 3, p. 351-8, outubro 2008.

FERREIRA, A.S. Efeitos do Ultrassom Pulsado de Baixa intensidade na cicatrização por segunda intenção de lesões cutâneas totais em ratos, mediante avaliação por planimetria. 2005. 120pag. Mestrado - Bioengenharia. Departamento de Ortopedia. Faculdade de Medicina, USP. Ribeirão Preto.

FLEISCHNER, A.M. Plant extracts: to accelerate healing and reduce inflammation. Cosmetics e Toiletries, v. 100, p. 45-48, 1985.

GARROS, I.C. et al. Extrati de Passiflora edulis na cicatrização de feridas cutâneas abertas em ratos: estudo morfológico e histológico. Acta Cirúrgica Brasileira. , v. 21, p. 55, 2006.

GONÇALVES, G. e PARIZOTTO, N.A. (1998) Fisiologia da reparação cutânea: atuação da fisioterapia. Revista Brasileira de Fisioterapia 3: 5-13.

KOKUBU T. et al. Low intensity pulsed ultrasound exposure increases prostaglandin E2 production via the induction of cyclooxygenase-2 mRNA in mouse osteoblasts. Biochem Biophys Res Commun, v. 256, p. 284-287, 1999.

KUMAR V., ABBAS A.K. e FAUSTO N. Robbins e Cotran: Patologia - Bases patológicas das doenças. 7 ed. Rio de Janeiro: Editora Elsevier, 2005.

LORENZI, H.; MATOS, F.J.A. Plantas Medicinais do Brasil Nativas e Exóticas. São Paulo: Instituto Plantarum,2002.p.296.

MARCHINI, F.B. Estudo Morfológico e morfonético da Cicatrização de Feridas cutâneas abertas em ratos albinos com e sem 
tratamento com óleo de Rosa Mosqueta. 1994. 150pag. Mestrado. Departamento de Morfologia. Escola Paulista de Medicina Universidade Federal de São Paulo, São Paulo.

MEDEIROS, A.C. et al. Tratamento tópico de queimaduras do dorso de ratos com ácido hialurônico. Acta Cirúrgica Brasileira., São Paulo, v. 14, n. 4, 1999.

MENDONÇA, A.C. ; FERREIRA, A.S. ; BARBIERI, C.H.; THOMAZINE, J.A.; MAZZER, N. Efeitos do ultra-som pulsado de baixa intensidade sobre a cicatrização por segunda intenção de lesões cutâneas totais em ratos. Acta Ortopédica

Brasileira, v. 14, n. 3, p. 152-7, 2006.

MINATEL, D.G; PEREIRA, A.M.S.; CHIARETTI, T.M.; PASQUELIN, L.;OLIVEIRA, J.C. N.; COUTO, L.B.; LIA, R.C.C.; CINTRA, J.M.; BEZZON, M.F.A; FRANCA,S.C. Estudo clínico para validação da eficácia de pomada contendo barbatimão (Stryphnodendron adstringens (Mart.) Covelle) na cicatrização de úlceras de decúbito. Revista Brasileira de Medicina, v. 7, p. 67, 2010.

NETO, J.J.; FRACASSO, J.F.; NEVES, M.C.L.C.; SANTOS, L.E.; BANUTH, V.L.Tratamento de ulcera varicosa e lesões de pele com calêndula officinales /ou com

Shyphonodendron barbaderiman (Vellozo)

Martius. Revista de ciências farmacêuticas, São Paulo, v. 17, p. 181-186, 1966.

PALASTANGA, N.; FIERTH, D. ; SOAMES, R. Anatomia e movimento humano: estrutura e função. São Paulo: Manolle, 2000.
PARVIZI, J. et al. Calcium signaling is required for ultrasound-stimulated aggrecan synthesis by rat chondrocytes. Journal of Orthopaedic Research, v. 20, p. 51-57, 2002.

RYABY, J.T. et al. Low intensity pulsed ultrasound increases calcium incorporation in both differentiating cartilage and bone cell cultures. Transactions of the Orthopedic Research Society, v. 14, p. 15, 1989.

SANTOS, S.C. et al. Tannin composition of barbatimão species. Fitoterapia, v. 73, p. 292-299, 2002.

SELVA, E.A. O extrato aquoso do Barbatimão como cicatrizante em fendas cirúrgicas do tecido cutâneo em gatos. 2006. 86pag Trabalho de monografia de conclusão do curso de pósgraduação. Departamento de clinica médica e cirurgia de pequenos animais. UCB. Campo Grande.

SMELTHZER, S.C.; BARE, B.G. Tratado de enfermagem médico-cirúrgica. 10 ed. Rio de Janeiro: Guanabara Koogan,2005.vol 2, 198 pag.

STEVENS, A. \& LOWE, J. Respostas teciduais ao dano. In: Patologia. 2 ed. São Paulo: Manole, 2000. p. 35-50.

YOUNF, S. Eletroterapia: prática baseada em evidências. 11. ed. São Paulo: Manole, 2003.230 pag.

YOUNG, S.R.; DYSON, M. Effect of Therapeutic ultrasound on the healing of full thickness excised skin lesions. Ultrasound, London, v. 28, p. 175180, 1990a.

RECEBIDO EM 16/6/2013

ACEITO EM 7/7/2013 